\title{
Kinetic Evaluation of Colour, Texture, Polyphenols and Antioxidant Capacity of Irish York Cabbage After Blanching Treatment
}

Amit Jaiswal

Technological University Dublin, amit.jaiswal@tudublin.ie

Shilpi Gupta

shilpi.19may@gmail.com

Nissreen Abu-Ghannam

Technological University Dublin, nissreen.abughannam@tudublin.ie

Follow this and additional works at: https://arrow.tudublin.ie/schfsehart

Part of the Microbiology Commons

\section{Recommended Citation}

Jaiswal, A. K., Gupta, S. \& Abu-Ghannam, N. (2011). Kinetic Evaluation of Color, Texture, Polyphenols and Antioxidant Capacity of Irish York Cabbage after Blanching Treatment. Food Chemistry DOI:10.1016/ j.foodchem.2011.08.032

This Article is brought to you for free and open access by the School of Food Science and Environmental Health at ARROW@TU Dublin. It has been accepted for inclusion in Articles by an authorized administrator of ARROW@TU

Dublin. For more information, please contact arrow.admin@tudublin.ie, aisling.coyne@tudublin.ie, gerard.connolly@tudublin.ie.

Funder: Irish Government under the Technological Sector Research Scheme (Strand III) of the National Development Plan

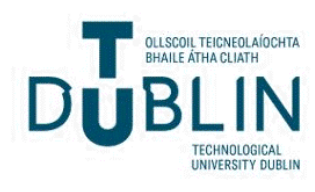




\title{
Kinetic evaluation of colour, texture, polyphenols and antioxidant capacity of Irish York cabbage after blanching treatment
}

\author{
Amit Kumar Jaiswal, Shilpi Gupta, Nissreen Abu-Ghannam* \\ School of Food Science and Environmental Health, College of Sciences and Health, Dublin Institute of Technology, Cathal Brugha Street, Dublin 1, Ireland
}

\section{A R T I C L E I N F O}

Article history:

Received 11 July 2011

Received in revised form 4 August 2011

Accepted 9 August 2011

Available online $\mathrm{xxxx}$

\section{Keywords:}

Antioxidant activity

Blanching

Colour

Kinetic models

Polyphenols

Texture

York cabbage

\begin{abstract}
A B S T R A C T
York cabbage was blanched between 80 and $100{ }^{\circ} \mathrm{C}$ with an increment of $5{ }^{\circ} \mathrm{C}$ for up to 14 min and kinetics of the different physicochemical properties were studied. Significant reductions in the texture, colour, polyphenols (PPs) and antioxidant (AO) capacity were observed due to blanching. Total phenolic and flavonoid content retained ranged from $19.6-24.5 \%$ to $22.0-25.7 \%$, respectively. Heavy losses in the AO capacity of $74.0-82.0 \%$ also occurred as a result of blanching. Blanching caused a significant reduction in firmness of $24.0-73.2 \%$ and a similar trend was also observed for colour. Kinetic evaluation of degradation was carried out for all the studied quality parameters. The fractional conversion first-order reaction model showed a good fit for the different studied parameters, with coefficients of determination ranging from 0.892 to 0.992 , except for texture and colour, which followed first order and zero order kinetics, respectively. The temperature effect followed the Arrhenius law, with activation energies for polyphenolic content, AO capacity, colour and texture calculated as 9.22-11.5, 9.05-35.05, 15.73 and $33.8 \mathrm{~kJ} / \mathrm{mol} \mathrm{K}$, respectively.
\end{abstract}

(c) 2011 Elsevier Ltd. All rights reserved.

\section{Introduction}

Cabbage (Brassica oleracea capitata), a member of Brassicaceae family (Cruciferae), is an economically and nutritionally important vegetable consumed widely around the globe (Singh, Sharma, \& Singh, 2009). It is rich in phytochemicals such as phenolic acids, flavonoids and glucosinolates and their hydrolysis products and is a good source of health-promoting compounds that show preventive effect against cancer, atherosclerosis, nephritis and diabetes mellitus (Taveira et al., 2009). Flavonoids can act in vitro as scavengers of active oxygen species and electrophiles, and as chelators of metal ions, and thus may be beneficial in vivo to reduce the risk of cardiovascular diseases (Hollman, 2001). Phenolic acids, such as caffeic, chlorogenic, sinapic, ferulic and p-coumaric acids, possess strong AO activity, due to the inhibition of lipid oxidation and scavenging reactive oxygen species (Sroka \& Cisowski, 2003).

Vegetables are primarily consumed in the cooked form and are processed by various techniques. Blanching is a short heat treatment that is typically applied to vegetables prior to further processing with the aim of enhancing both safety and quality attributes. Blanching imparts benefits, such as destruction of surface microflora of vegetables and enhancing the colour and texture and also the keeping quality of vegetable products. The quality of blanched product depends significantly on the time and tempera-

\footnotetext{
* Corresponding author. Tel.: +3531 402 7570; fax: +3531 8788978.

E-mail address: nissreen.abughannam@dit.ie (N. Abu-Ghannam).
}

ture of blanching and also on the size of vegetable to be blanched. Under-blanching speeds up the activity of enzymes and is worse than no blanching. Over-blanching causes loss of texture, colour, phytochemicals and minerals. Industrial blanching processes involve temperatures ranging from 70 to $95^{\circ} \mathrm{C}$ and times usually no higher than $10 \mathrm{~min}$ (Morales-Blancas, Chandia, \& CisnerosZevallos, 2002); whereas for domestic purposes vegetables are generally blanched for $10-12 \mathrm{~min}$ in boiling water $\left(98-100^{\circ} \mathrm{C}\right)$. A considerable amount of research has been done to understand the effects of blanching on texture, colour, phytochemical content and AO activity of different vegetables. Oboh (2005) and Wen, Prasad, Yang, and Ismail (2010) have observed the blanching effect on the degradation of vegetables' nutrient contents and AO properties. Volden et al. (2008) showed the effects of blanching of red cabbage on the levels of glucosinolates, polyphenols and anthocyanins, as well as for the AO potential by the ferric reducing ability power (FRAP) and oxygen radical absorbance capacity (ORAC) assays.

Data on the effect of blanching on physicochemical properties of cabbage is scarce (Amin \& Lee, 2005; Volden et al., 2008). Authors observed that the literature lacks information on kinetic evaluation of phytochemicals upon blanching both in terms of empirical models and structured models. Knowledge regarding the kinetics of physicochemical properties is essential to predict quality losses during the blanching process. Kinetic data will facilitate the inclusion of these quality aspects into the design of optimal processing conditions, which will be important for the development of new food products. A number of kinetic models 
such as zero order, first order and fractional conversion (FC) first order have been used for the phytochemical contents, AO capacity, texture and colour degradation for a range of fruits and vegetables (Gonçalves, Pinheiro, Abreu, Brandão, \& Silva, 2010). This work investigates the effects of blanching on the degradation kinetics of a number of physicochemical properties, such as texture, colour, PPs, and AO activity.

\section{Materials and methods}

\subsection{Plant materials and their preparation}

Fresh Irish York cabbage was purchased from a local supermarket in Dublin in April 2010. Eighteen to twenty York cabbage heads $(25-30 \mathrm{~kg})$ were randomly selected and trimmed of their outer leaves and stem. The heads were then divided into four segments and the central core was removed. The segments were chopped into $0.5 \times 5-6 \mathrm{~cm}$ pieces, using a vegetable cutting machine. A pooled batch of about $18 \mathrm{~kg}$ chopped cabbage was stored in a plastic bag under dark refrigerated conditions $\left(4 \pm 0.5^{\circ} \mathrm{C}\right)$ for $4-5$ days and was utilised as the raw material for all subsequent treatments. A 50-g sample was taken from the pooled batch (in duplicate) as a reference for fresh, unprocessed cabbage.

\subsection{Blanching}

Blanching was carried out by immersing cabbage in hot water using a wire mesh basket (cylindrical, $10 \mathrm{~cm}$ diameter and $15 \mathrm{~cm}$ height). The basket containing $50 \mathrm{~g}$ cut cabbage was immersed in a thermostatically controlled water bath $\left( \pm 0.5^{\circ} \mathrm{C}\right)$ containing $5 \mathrm{~L}$ water. Blanching was carried out between 80 and $100^{\circ} \mathrm{C}$ with an increment of $5{ }^{\circ} \mathrm{C}$. For all the temperatures, samples were withdrawn every 2 min up to $14 \mathrm{~min}$. The blanched material was drained, cooled in ice water $\left(1-4^{\circ} \mathrm{C}\right)$ for $1 \mathrm{~min}$ and then allowed to drain for $30 \mathrm{~s}$. The blanched samples were kept in a plastic bag $(20 \times 25 \mathrm{~cm})$ and colour and texture analysis were carried out on the same day. The treatments were randomised and were performed in duplicate. The processed samples were submerged in liquid nitrogen and ground to a coarse powder using a mortar and pestle and stored in plastic bags at $-20^{\circ} \mathrm{C}$ until further analysis (10-15 days).

\subsection{Preparation of extracts}

A 5-g sample of crushed cabbage sample was extracted using $60 \%$ methanol with 1 min nitrogen flushing. Flasks were kept in a shaking incubator (Innova 42, Mason Technology, Dublin, Ireland) at $100 \mathrm{rpm}$ and $40^{\circ} \mathrm{C}$ for $2 \mathrm{~h}$. The infusions were filtered through Whatman \#1, until a clear extract was obtained. The extracts were evaporated to dryness in a multi-evaporator (Syncore Polyvap, Mason Technology) at $60^{\circ} \mathrm{C}$ and stored at $-20^{\circ} \mathrm{C}$ until used.

\subsection{Phytochemical analysis}

\subsubsection{Determination of total polyphenolic content}

Total polyphenolic content (TPC) of vegetable extracts was determined by the method of Ganesan, Kumar, and Bhaskar (2008) using Folin-Ciocalteau's phenol reagent (Sigma-Aldrich, Steinheim, Germany). Results were expressed as $\mathrm{mg}$ gallic acid (Sigma-Aldrich,) equivalents per $100 \mathrm{~g}$ (mg GAE/100 g) fresh weight ( $\mathrm{fw}$ ) of cabbage through the calibration curve of gallic acid.

\subsubsection{HPLC-DAD analysis of polyphenolic compounds}

The HPLC-DAD analysis of polyphenolic compounds of fresh and blanched cabbage extracts were measured according to an existing method in our laboratory (Jaiswal, Rajauria, Abu-Ghannam, \& Gupta, 2011). In brief, the HPLC system consisted of a reversed-phase HPLC column on an Alliance HPLC (Waters, e2695 Separations modules) equipped with an autosampler and controller with dual pump, a 2998 photodiode array detector (PDA) and Empower software. An Atlantis C18 column $(250 \times 4.6 \mathrm{~mm}, 5 \mu \mathrm{m}$ particle size $)$ from Waters (Waters, Milford, MA) was used for polyphenolic separation at $25{ }^{\circ} \mathrm{C}$. All the solvents used were similar to our earlier report (Jaiswal et al., 2011). The chromatogram was monitored at $280 \mathrm{~nm}$.

\subsubsection{Determination of total flavonoid content}

The total flavonoid content (TFC) was determined according to the method of Liu, Lin, Wang, Chen, and Yang (2009) and results were expressed as mg quercetin (Sigma-Aldrich) equivalents per $100 \mathrm{~g}$ (mg QE/100 g) (fw) of cabbage.

\subsection{AO capacity analysis}

In the present study four different methods [2,2-diphenyl-1picrylhydrazyl free radical scavenging capacity (DPPH RSC), ferric-reducing antioxidant potential (FRAP) assay, lipid peroxidation in a haemoglobin-induced linoleic acid system (LPO) and hydrogen peroxide $\left(\mathrm{H}_{2} \mathrm{O}_{2}\right)$ scavenging assay] were used for the estimation of total AO capacity of the fresh and blanched York cabbage. All the methods were carried out according to the existing protocols in our laboratory (Rajauria, Jaiswal, Abu-Ghannam, \& Gupta, 2010). For the DPPH RSC and LPO inhibitory ability, ascorbic acid was used as a reference compound and the results were expressed as $\mathrm{mg}$ ascorbic acid equivalents per $100 \mathrm{~g}$ ( $\mathrm{mg} \mathrm{AscE} / 100 \mathrm{~g}$ ) (fw) of cabbage. Trolox (Sigma-Aldrich) was used as a standard for FRAP assay and the results were expressed as $\mathrm{mg}$ Trolox equivalents per $100 \mathrm{~g}$ ( $\mathrm{mg} \mathrm{TE} / 100 \mathrm{~g}$ ) ( $\mathrm{fw}$ ) of cabbage; whereas BHT was used as a reference compound for $\mathrm{H}_{2} \mathrm{O}_{2}$-scavenging capacity and the results were expressed as mg BHT equivalents per $100 \mathrm{~g}$ (mg BHTE/ $100 \mathrm{~g}$ ) (fw) of cabbage.

\subsection{Instrumental texture analysis}

The texture of the raw and processed samples was analyzed using an Instron texture analyzer (Instron 4302 Universal Testing Machine, Canton MA, USA). The texturometer was mounted with a 500 Newton $(\mathrm{N})$ load cell and equipped with a Warner-Bratzler Blade (V-notch blade) which cut through the sample at a download speed of $50 \mathrm{~mm} / \mathrm{min}$. A $5 \mathrm{~g}$ sample was placed on two parallel bars with a gap of $10 \mathrm{~mm}$ between them. The maximum force $(N)$ required to shear the sample was used as an indication of firmness. Data were analyzed by using Bluehill software. The firmness of 12 samples was measured individually and an average firmness value was calculated.

\subsection{Instrumental colour analysis}

The colour of the raw and blanched cabbage was analysed using a Colour Quest XE colorimeter (Hunter Lab, Think-Stothard Ltd., Mountsorrel, UK). Before measuring, the colorimeter was calibrated using a white reference tile and a light trap (black tile). Five random areas were measured through the plastic pockets (in duplicate) and mean values (total 10 readings/sample) were reported for each treatment. The Hunter Lab co-ordinates [ $L^{*}$ (lightness, 0 for black to 100 for white), $a^{*}$ (red-green) and $b^{*}$ (yellow-blue)] were measured using the $L^{*}, a_{*}$ and $b^{*}$ Hunter scale parameters. Chroma was calculated according to the Eq. (1):

$C=\sqrt{a^{2}+b^{2}}$ 


\subsection{Mathematical models and kinetic analysis}

The kinetics of York cabbage phenolic content, flavonoid content, different AO capacity, texture (firmness) change and colour change were described by fitting a zero order (Eq. (2)) or a first-order kinetic model (Eq. (3)) to the experimental data:

$A=A_{0}-k t$,

$\frac{A}{A_{0}}=e^{-k t}$,

where, $A$ is the parameter to be estimated, the subscript 0 indicates the initial value of the parameter, $t$ is the blanching time, and $k$ is the rate constant at temperature $T$. For the parameter estimation, the individual measured concentrations were used instead of mean values of duplicate or triplicate experiments, thus taking into account variability within the samples.

When any quality parameter varies from an initial value until a residual value, which is further retained, the so-called fractional conversion model based on first-order kinetics (Eq. (4)) can also be considered: The subscript "eq" indicates equilibrium value.

$\frac{A-A_{\mathrm{eq}}}{A_{0}-A_{\mathrm{eq}}}=e^{-k t}$

The temperature dependence of the rate constant $(k)$ can be expressed by the Arrhenius equation (Eq. (5)):

$k=k_{\text {ref }} \exp \left[-\frac{E_{a}}{R}\left(\frac{1}{T}\right)\right]$

where, $k_{\text {ref }}$ is the reaction constant at the infinite temperature; $E_{a}$ is an activation energy; $R$ is the gas constant $(8.3145 \mathrm{~J} / \mathrm{mol} \mathrm{K})$; and $T$ is absolute temperature (in kelvin). The activation energy can be obtained through linear regression of the logarithm of the rate constant $v s$. the inverse of temperature.

\subsection{Statistical analysis}

All experiments were done in triplicate and replicated twice. Results are expressed as mean values \pm standard deviation. All the statistical analysis and data were fitted to models using STATGRAPHICS Centurion XV. The coefficient of determination and mean square error were used as criteria for adequacy of fit.

\section{Results and discussion}

\subsection{Effects of blanching on phytochemical content}

\subsubsection{Changes in TPC}

The major contribution to the AO activities of plant foods is related to their content of polyphenols. Therefore, it is important to consider the effect of blanching treatments on the TPC of the vegetables. The TPC of fresh cabbage was $147.5 \pm 6.63 \mathrm{mg}$ GAE/100 g of fw. The results from the present study are in line with reported results. Kim, Padilla-Zakour, and Griffiths (2004) reported that TPC of cabbage ranged from 110.2 to $153.3 \mathrm{mg} / 100 \mathrm{~g}$ of fw.

Fig. 1(a) shows TPC of fresh and blanched York cabbage. As can be seen, blanching caused significant reduction in the TPC, which could be due to thermal degradation and leaching into the water (Gonçalves et al., 2010). According to Joubert (1990), blanching causes solubilisation of phenolic compounds and hence leads to a reduction in TPC. For all the temperatures studied, blanching for up to 2 min resulted in a severe loss of phenolic compounds. Reduction in the range of $43.5-45.4 \%$ was observed at lower blanching temperatures $\left(80,85\right.$ and $90^{\circ} \mathrm{C}$ ) whereas $47.3-50.4 \%$ reduction was observed at 95 and $100{ }^{\circ} \mathrm{C}$ after 2 min. The degradation continued up to $6 \mathrm{~min}$ of blanching time resulting in a
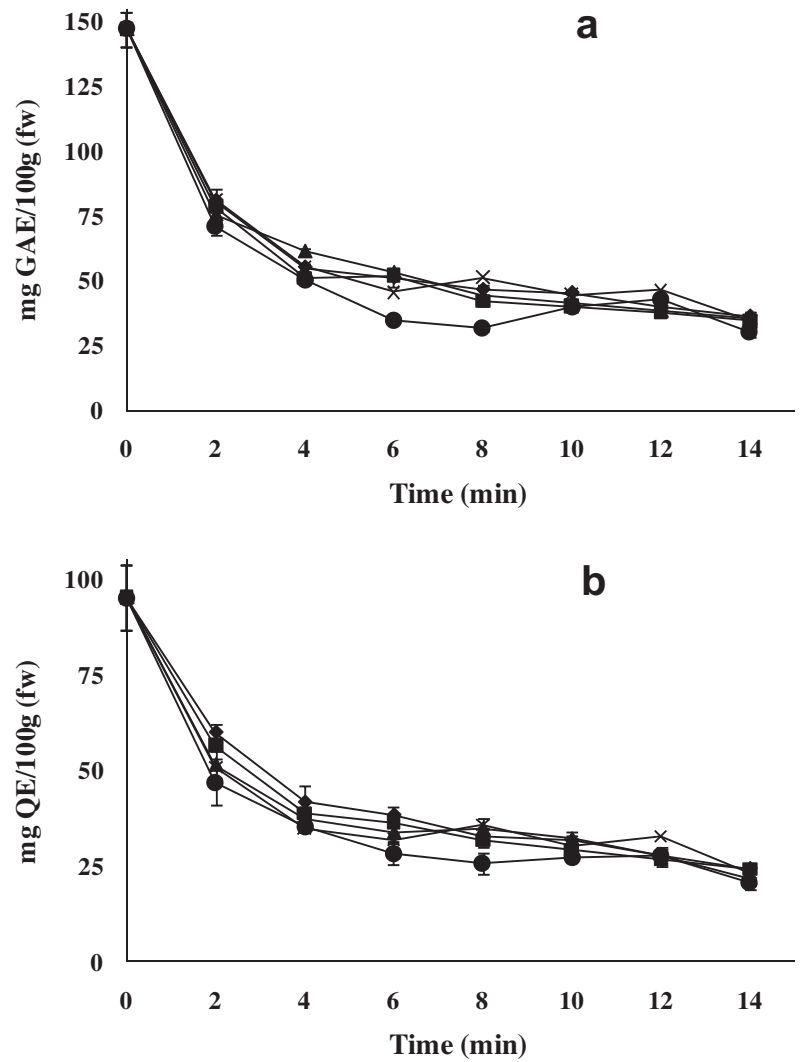

Fig. 1. Effect of blanching temperature (80 (- -), 85(-口-), $90(-\mathbf{\Delta - )}, 95$ (*) and $\left.100{ }^{\circ} \mathrm{C}(-\mathbf{-})\right)$ and time combinations on (a) total phenolic content and (b) total flavonoid content of York cabbage.

reduction of $63.9-65.3 \%$ at $80-90{ }^{\circ} \mathrm{C}$ and $69.1-76.5 \%$ at 95 and $100{ }^{\circ} \mathrm{C}$, as compared to fresh cabbage. As the blanching time increased beyond 6 min (until $14 \mathrm{~min}$ ), there was no further reduction in TPC and it became almost constant for most of the blanching temperatures studied. This finding is in contrast to much published work wherein it has been pointed out that an increase in the blanching time results in a continuous loss of phytochemicals.

However, an interesting observation was that when the phytochemical content was compared in terms of per gram dry weight of cabbage extract, blanching at higher temperatures $\left(95^{\circ} \mathrm{C}\right.$ for $12-$ $14 \mathrm{~min}$ ) resulted in a $5-12 \%$ increase in the TPC. A similar pattern was observed at $100{ }^{\circ} \mathrm{C}$. This may be attributed to the inactivation of the polyphenol oxidase enzyme during blanching, leading to the inhibition of polyphenols degradation (Yamaguchi et al., 2003).

\subsubsection{Changes in TFC}

Flavonoids are potent AO, free radical scavengers, and metal chelators and inhibit lipid peroxidation. Fresh cabbage showed the presence of a considerable TFC $(95.4 \pm 8.40 \mathrm{mg} \mathrm{QE} / 100 \mathrm{~g}$ of $\mathrm{fw})$. These values are within the range of those reported elsewhere for cabbage. Andarwulan, Batari, Sandrasari, Bolling, and Wijaya (2010) studied the flavonoid contents of 11 vegetables from west Java, Indonesia and found that they varied from 0.3 to $143 \mathrm{mg} /$ $100 \mathrm{~g}$ (fw), whereas Lin and Tang (2007) reported variation from 4.1 to $133.1 \mathrm{mg} \mathrm{QE} / 100 \mathrm{~g}$ (fw).

The changes in the TFC of York cabbage after blanching from $80-100{ }^{\circ} \mathrm{C}$ as a function of blanching time are presented in Fig. 1(b). Similar trends in the changes of TFC were observed at all the five blanching temperatures. Overall a reduction of $74.4 \%$, $74.5 \%, 77.1 \%, 75.6 \%$ and $78.0 \%$ was observed as a result of blanching at $80,85,90,95$ and $100{ }^{\circ} \mathrm{C}$, respectively after $14 \mathrm{~min}$. Maximal loss of TFC occurred in the first 2 min, accounting for $37.0-50.6 \%$ loss 
over the range of temperatures studied. The degradation continued for up to 6 min of blanching accounting for a total 59.6-71.0\% loss of TFC from $80-100{ }^{\circ} \mathrm{C}$. Blanching beyond $6 \mathrm{~min}$ did not have a severe effect on the TFC and the values almost became constant.

\subsubsection{HPLC-DAD analysis of polyphenolic compounds}

Fig. 2 shows the HPLC chromatogram at $280 \mathrm{~nm}$ for the polyphenolic compounds present in the fresh and blanched $\left(95^{\circ} \mathrm{C}\right.$ for $12 \mathrm{~min}$ ) York cabbage. Fig. 2(a) shows the chromatogram for the
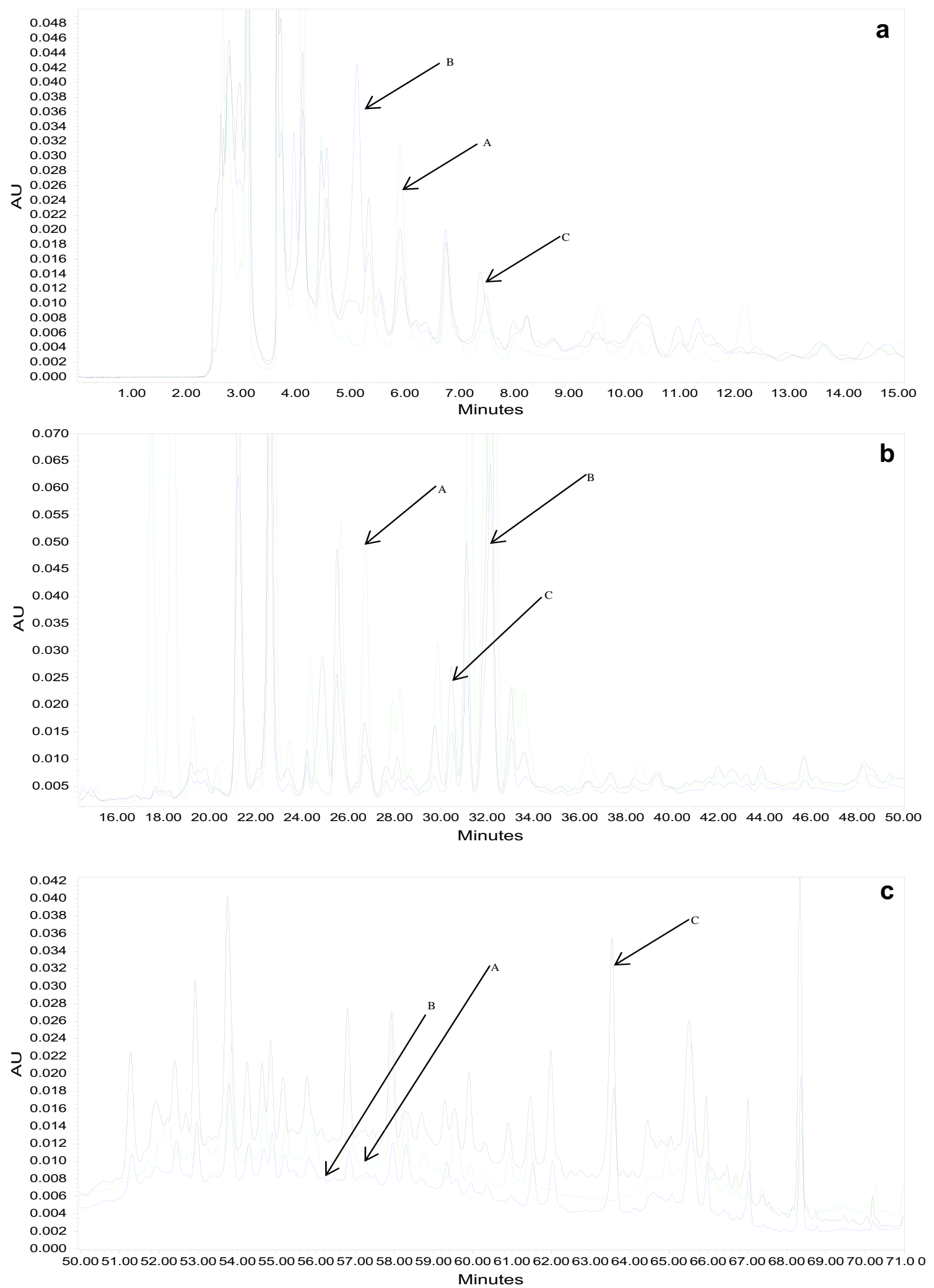

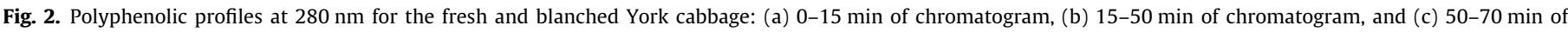
chromatogram ((A) fresh cabbage, (B) 6 min of blanching at $95^{\circ} \mathrm{C}$, and (C) 12 min of blanching at $95^{\circ} \mathrm{C}$ ).

Please cite this article in press as: Jaiswal, A. K., et al. Kinetic evaluation of colour, texture, polyphenols and antioxidant capacity of Irish York cabbage after blanching treatment. Food Chemistry (2011), doi:10.1016/j.foodchem.2011.08.032 
first 15 min of elution; compounds eluting in this period are generally simple polyphenols, such as hydroxybenzoic acid derivatives. The chromatogram shows that there was a continuous reduction in the individual compounds other than the peak at 5 min, which increased after 6 min of blanching at $95{ }^{\circ} \mathrm{C}$.

Fig. 2(b) exhibits the chromatogram for 15-50 min of elution, during which compounds belonging to derivatives of hydroxycinnamic acid and flavonoids may generally be seen. The chromatogram shows that there was a significant reduction in the individual peaks after the entire blanching period. Blanching for 12 min showed slightly less deterioration in the individual peak compared to fresh cabbage, but it was higher than that of the 6 min blanching. Similar trends were observed at $100^{\circ} \mathrm{C}$. Results also showed that peaks for a few compounds completely vanished following blanching, regardless of blanching time and temperature. It is anticipated that these compounds could be highly hydrophilic and totally drained out in the water during blanching.

Fig. 2(c) presents the chromatogram from 50 to 70 min of elution. The compounds eluting in this region are generally flavonoids. There was a significant reduction in the individual peaks after 6 min of blanching; whereas 12 min of blanching showed enhancement in the level of individual compounds. A similar trend was also observed at $100^{\circ} \mathrm{C}$. According to Bunea et al. (2008) and Ranilla, Genovese, and Lajolo (2009), the increase in concentrations of certain phenolic compounds after heat processing treatments may be explained by their better release from the food matrix as a result of the breakdown of molecular structures containing phenolic groups, which accounts for the leaching of phenolic compounds into water or breakdown of the same.

\subsubsection{Kinetic analysis of phytochemical content}

Degradation kinetics of the phytochemical content was modelled using zero order (Eq. (2)), first-order (Eq. (3)) and FC first-order kinetics models (Eq. (4)). Mean square error (MSE) and coefficient of determination $\left(r^{2}\right)$ (Table 1 ) were used as statistical measures for comparison of the experimental and model simulated values. FC first-order kinetics model fitted the experimental data with high $r^{2}$ value, ranging from 0.892 to 0.983 at 80 to $100{ }^{\circ} \mathrm{C}$ with low MSE (Table 1). This was expected as the raw data clearly showed an initial degradation followed by an almost constant retention of the content. Experimental and predicted (FC first-order kinetics models) data for degradation of TPC and TFC due to blanching at three temperatures $\left(80,90\right.$ and $\left.100{ }^{\circ} \mathrm{C}\right)$ are presented in Fig. 3(a) and 3(b), respectively. Similar results were obtained for the other temperatures (data not shown). For the TPC, the degradation rate constant $(k)$ increases from 0.379 to $0.484 \mathrm{~min}^{-1}$ when
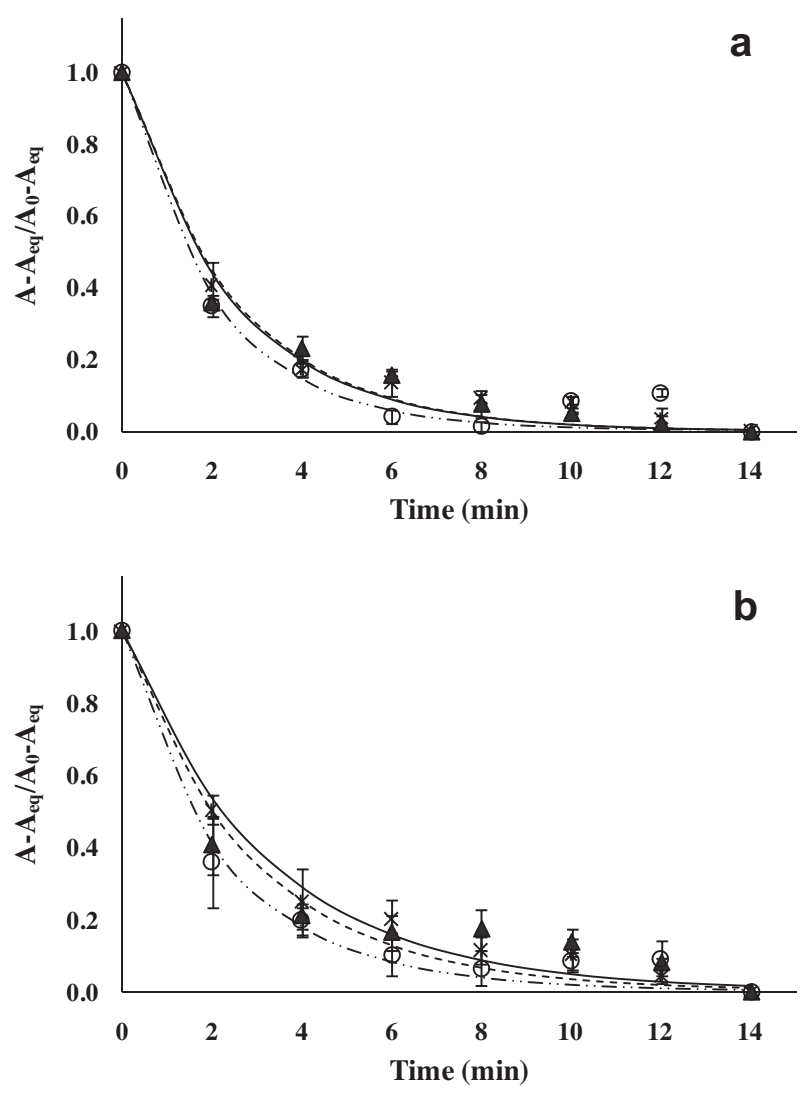

Fig. 3. Experimental $\left[80(\boldsymbol{K}), 90(\mathbf{\Lambda})\right.$ and $\left.100{ }^{\circ} \mathrm{C}(\mathrm{O})\right]$ and predicted $[80(-), 90$ $(--)$ and $100^{\circ} \mathrm{C}(-\cdot-)$ ] (FC first-order kinetics model) data for blanching temperature and time combinations on (3a) total phenolic content and (3b) total flavonoid content of York cabbage.

the temperature increases from 80 to $100^{\circ} \mathrm{C}$. TFC degradation rate also showed a similar trend where $k$ increases from 0.314 to $0.366 \mathrm{~min}^{-1}$ as a result of temperature increase. The temperature dependence of the rate constant for both TPC and TFC was well expressed by the Arrhenius equation (Eq. (5)). The resulting activation energy was $11.54 \mathrm{~kJ} / \mathrm{mol} \mathrm{K}$ for TPC and $9.22 \mathrm{~kJ} / \mathrm{mol} \mathrm{K}$ for TFC with $r^{2}$ values of 0.901 and 0.870 , respectively. The low activation energies clearly showed that these quality attributes were highly temperature sensitive and even slight adverse conditions can result in the loss of these compounds from the plant cell.

Table 1

Kinetic parameter estimates, corresponding regression coefficient and mean square errors of York cabbage phytochemical degradation due to blanching.

\begin{tabular}{|c|c|c|c|c|c|c|c|}
\hline & \multirow[t]{2}{*}{ Temperature $\left({ }^{\circ} \mathrm{C}\right)$} & \multicolumn{3}{|l|}{ First order } & \multicolumn{3}{|c|}{ Fractional conversion first order } \\
\hline & & $k$ & $r^{2}$ & MSE & $k$ & $r^{2}$ & MSE \\
\hline \multirow[t]{5}{*}{ TPC } & 80 & $0.149 \pm 0.00$ & 0.764 & 0.015 & $0.379 \pm 0.04$ & 0.983 & 0.002 \\
\hline & 85 & $0.166 \pm 0.00$ & 0.773 & 0.015 & $0.416 \pm 0.02$ & 0.981 & 0.002 \\
\hline & 90 & $0.163 \pm 0.01$ & 0.783 & 0.014 & $0.424 \pm 0.00$ & 0.977 & 0.003 \\
\hline & 95 & $0.165 \pm 0.01$ & 0.726 & 0.017 & $0.432 \pm 0.00$ & 0.960 & 0.004 \\
\hline & 100 & $0.203 \pm 0.02$ & 0.740 & 0.018 & $0.484 \pm 0.04$ & 0.977 & 0.003 \\
\hline \multirow[t]{5}{*}{ TFC } & 80 & $0.136 \pm 0.02$ & 0.846 & 0.010 & $0.314 \pm 0.05$ & 0.892 & 0.002 \\
\hline & 85 & $0.145 \pm 0.02$ & 0.805 & 0.012 & $0.337 \pm 0.02$ & 0.982 & 0.002 \\
\hline & 90 & $0.148 \pm 0.02$ & 0.725 & 0.016 & $0.349 \pm 0.05$ & 0.935 & 0.007 \\
\hline & 95 & $0.148 \pm 0.03$ & 0.637 & 0.021 & $0.376 \pm 0.03$ & 0.928 & 0.007 \\
\hline & 100 & $0.180 \pm 0.04$ & 0.741 & 0.017 & $0.366 \pm 0.90$ & 0.971 & 0.003 \\
\hline
\end{tabular}

$k$, kinetic parameter estimates.

$r^{2}$, regression coefficient.

MSE, mean square errors.

TPC, total phenolic content.

TFC, total flavonoid content. 


\subsection{Effect of blanching on AO capacity}

\subsubsection{Changes in DPPH radical scavenging capacity}

The effect of blanching temperature and time on DPPH RSC of York cabbage is presented in Fig. 4(a). The DPPH RSC of fresh cabbage estimated was $187.6 \pm 8.08 \mathrm{mg}$ AscE/ $100 \mathrm{~g}$ of fw. Results showed that there was a reduction in DPPH RSC after blanching. Similar to the phytochemical content, at the lower blanching temperatures $\left(80-90^{\circ} \mathrm{C}\right)$ there was a significant loss (60-65\%) in DPPH RSC up to 6 min of blanching. The rate of loss gradually reduced as the blanching time was increased finally resulting in almost constant values. This may be due to losses or degradation of certain types of phenolic compounds or other compounds responsible for DPPH RSC of York cabbage during blanching. This result supports the statement of Papetti, Daglia, and Gazzani (2002), who reported that the RSC would decrease if the vegetables were exposed to heat, such as with blanching. Similar trend was observed when cabbage was blanched at the higher temperatures $\left(95-100^{\circ} \mathrm{C}\right.$ ). There was a higher reduction in DPPH RSC up to $6 \mathrm{~min}$, in comparison to the lower temperature range, after which the DPPH RSC remained almost constant. Puupponen-Pimiä et al. (2003) measured the AO capacity by the DPPH assay in blanched cauliflower and reported a reduction of $20-30 \%$, which is less than that reported in the present study.

\subsubsection{Changes in $\mathrm{H}_{2} \mathrm{O}_{2}$ scavenging capacity}

In a previous study, it was reported that Irish York cabbage has a considerable ability to scavenge $\mathrm{H}_{2} \mathrm{O}_{2}$ (Jaiswal, Rajauria, AbuGhannam, \& Gupta, 2011). In the present study, there was reduction in the $\mathrm{H}_{2} \mathrm{O}_{2}$ scavenging capacity of the blanched York cabbage as compared to fresh (Fig. 4(b)). The $\mathrm{H}_{2} \mathrm{O}_{2}$ scavenging capacity of fresh cabbage was estimated to be $667.8 \pm 109.9 \mathrm{mg}$ BHTE/100 g of fw. Results showed that for all the different temperatures, maximal degradation occurred in the first $2 \mathrm{~min}$. Lower blanching temperatures $\left(80-90{ }^{\circ} \mathrm{C}\right.$ ) resulted in a $55.3-57.3 \%$ loss in $\mathrm{H}_{2} \mathrm{O}_{2}$ -
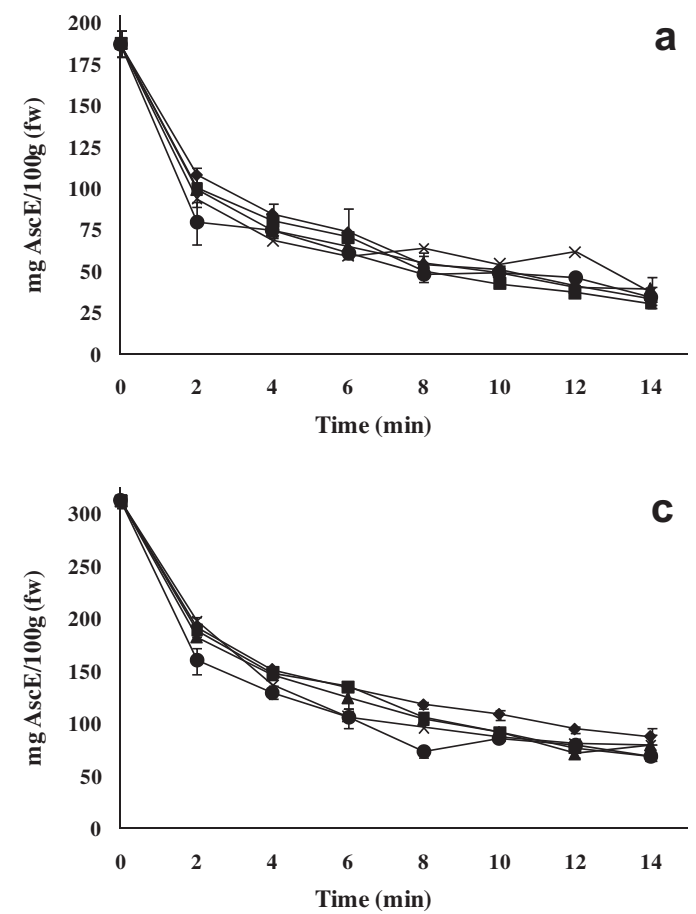

scavenging capacity until 6 to 8 min of blanching but subsequently the rate of loss became almost constant as the time of blanching increased. Blanching of cabbage at the higher temperatures (95$100{ }^{\circ} \mathrm{C}$ ) resulted in greater reduction in the $\mathrm{H}_{2} \mathrm{O}_{2}$ scavenging capacity (63.7-69.8\%) than that of the lower temperature for up to 6 min, after which the scavenging capacity was constant. In the case of all five temperatures, the $\mathrm{H}_{2} \mathrm{O}_{2}$ scavenging capacity was retained beyond 6 min of blanching.

\subsubsection{Changes in lipid peroxidation inhibitory ability}

Fig. 4(c) shows the inhibition of lipid peroxidation in the presence of fresh and blanched cabbage extracts. The LPO inhibitory ability of fresh cabbage was estimated to be $312.7 \pm 6.56 \mathrm{mg}$ AscE/100 g of fw. Blanching treatments produced a significant decrease in the LPO inhibitory ability in most cases with respect to their fresh counterparts. Similar to other AO systems, blanching at $80-90{ }^{\circ} \mathrm{C}$ resulted in $55-58 \%$ reduction in LPO inhibitory ability up to 6 min of blanching but subsequently the rate of loss reduced. As the blanching temperature increased $\left(95-100^{\circ} \mathrm{C}\right)$, the reduction in LPO inhibitory ability was higher (66-72\%), as compared to that at low temperature until 6-8 min of blanching. Heating beyond 8 min did not have any significant effect on the LPO inhibitory activity.

\subsubsection{Changes in ferric reducing $A O$ potential}

The experimental results of this study (Fig. 4(d)) indicate that fresh and blanched cabbage had the ability to reduce $\mathrm{Fe}^{3+}$ to $\mathrm{Fe}^{2+}$ in different proportions. However, fresh cabbage had relatively strong ferric ion reducing capacity $(26.4 \pm 0.13 \mathrm{mg} \mathrm{TE} / 100 \mathrm{~g}$ of fw) as compared to blanched cabbage. The reducing power of blanched cabbage decreased markedly with an increase in blanching time and temperature, although it reduced to different extents. The decrement was more noticeable after 6-8 min (32-35\% retention) of blanching. A similar result was reported by Amin and Lee (2005), who carried out a detailed study on the effect of the
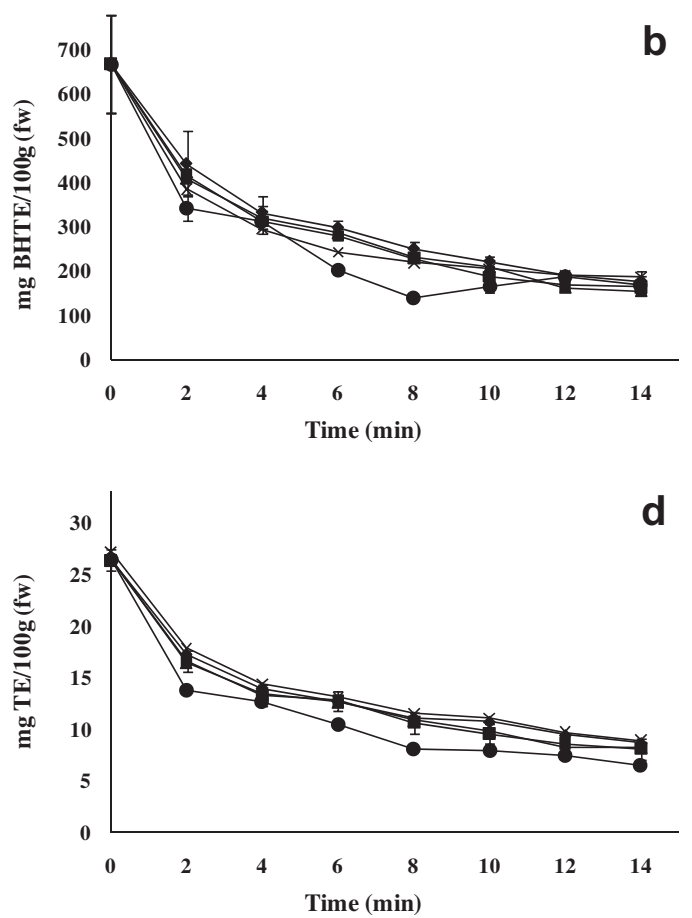

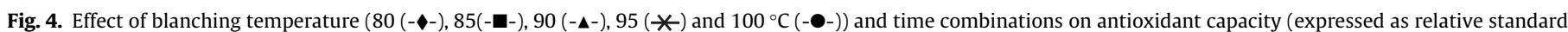

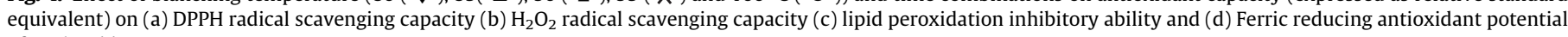
of York cabbage. 
blanching time for red cabbage, Chinese cabbage, cabbage, mustard cabbage, and Chinese white cabbage.

\subsubsection{Kinetic analysis of $A O$ capacity}

AO capacity analysis was modelled using zero order (Eq. (2)), first-order (Eq. (3)) and FC first-order (Eq. (4)). Table 2 shows deg-

Table 2

Kinetic parameter estimates, corresponding regression coefficient and mean square errors of York cabbage antioxidant capacity reduction due to blanching.

\begin{tabular}{|c|c|c|c|c|c|c|c|}
\hline & \multirow[t]{2}{*}{ Temperature $\left({ }^{\circ} \mathrm{C}\right)$} & \multicolumn{3}{|l|}{ First order } & \multicolumn{3}{|c|}{ Fractional conversion first order } \\
\hline & & $k$ & $r^{2}$ & MSE & $k$ & $r^{2}$ & MSE \\
\hline \multirow[t]{5}{*}{ DPPH } & 80 & $0.159 \pm 0.03$ & 0.902 & 0.007 & $0.269 \pm 0.03$ & 0.966 & 0.004 \\
\hline & 85 & $0.169 \pm 0.03$ & 0.903 & 0.007 & $0.312 \pm 0.02$ & 0.968 & 0.004 \\
\hline & 90 & $0.171 \pm 0.03$ & 0.837 & 0.011 & $0.351 \pm 0.06$ & 0.976 & 0.003 \\
\hline & 95 & $0.172 \pm 0.03$ & 0.684 & 0.020 & $0.367 \pm 0.04$ & 0.903 & 0.009 \\
\hline & 100 & $0.186 \pm 0.04$ & 0.764 & 0.018 & $0.414 \pm 0.04$ & 0.950 & 0.008 \\
\hline \multirow[t]{5}{*}{$\mathrm{H}_{2} \mathrm{O}_{2}$} & 80 & $0.124 \pm 0.03$ & 0.947 & 0.007 & $0.237 \pm 0.03$ & 0.982 & 0.006 \\
\hline & 85 & $0.140 \pm 0.03$ & 0.903 & 0.006 & $0.271 \pm 0.02$ & 0.984 & 0.002 \\
\hline & 90 & $0.138 \pm 0.03$ & 0.903 & 0.006 & $0.275 \pm 0.06$ & 0.979 & 0.002 \\
\hline & 95 & $0.144 \pm 0.03$ & 0.793 & 0.012 & $0.398 \pm 0.04$ & 0.991 & 0.001 \\
\hline & 100 & $0.172 \pm 0.04$ & 0.790 & 0.014 & $0.437 \pm 0.04$ & 0.958 & 0.005 \\
\hline \multirow[t]{5}{*}{ LPO } & 80 & $0.124 \pm 0.00$ & 0.829 & 0.009 & $0.237 \pm 0.03$ & 0.982 & 0.002 \\
\hline & 85 & $0.140 \pm 0.00$ & 0.899 & 0.007 & $0.271 \pm 0.03$ & 0.977 & 0.003 \\
\hline & 90 & $0.143 \pm 0.00$ & 0.868 & 0.009 & $0.275 \pm 0.05$ & 0.980 & 0.002 \\
\hline & 95 & $0.150 \pm 0.00$ & 0.863 & 0.012 & $0.398 \pm 0.04$ & 0.991 & 0.001 \\
\hline & 100 & $0.172 \pm 0.01$ & 0.808 & 0.013 & $0.437 \pm 0.08$ & 0.975 & 0.003 \\
\hline \multirow[t]{5}{*}{ FRAP } & 80 & $0.105 \pm 0.01$ & 0.816 & 0.009 & $0.285 \pm 0.01$ & 0.981 & 0.002 \\
\hline & 85 & $0.104 \pm 0.01$ & 0.825 & 0.009 & $0.295 \pm 0.02$ & 0.975 & 0.003 \\
\hline & 90 & $0.114 \pm 0.02$ & 0.825 & 0.009 & $0.300 \pm 0.03$ & 0.973 & 0.003 \\
\hline & 95 & $0.126 \pm 0.02$ & 0.865 & 0.008 & $0.310 \pm 0.03$ & 0.968 & 0.003 \\
\hline & 100 & $0.144 \pm 0.03$ & 0.794 & 0.012 & $0.345 \pm 0.04$ & 0.960 & 0.004 \\
\hline
\end{tabular}

$k$, kinetic parameter estimates.

$r^{2}$, regression coefficient.

MSE, mean square errors.

DPPH, 2,2-diphenyl-1-picrylhydrazyl free radical scavenging capacity.

$\mathrm{H}_{2} \mathrm{O}_{2}$, hydrogen peroxide scavenging assay.

LPO, lipid peroxidation in a haemoglobin-induced linoleic acid system.

FRAP, ferric reducing antioxidant potential.
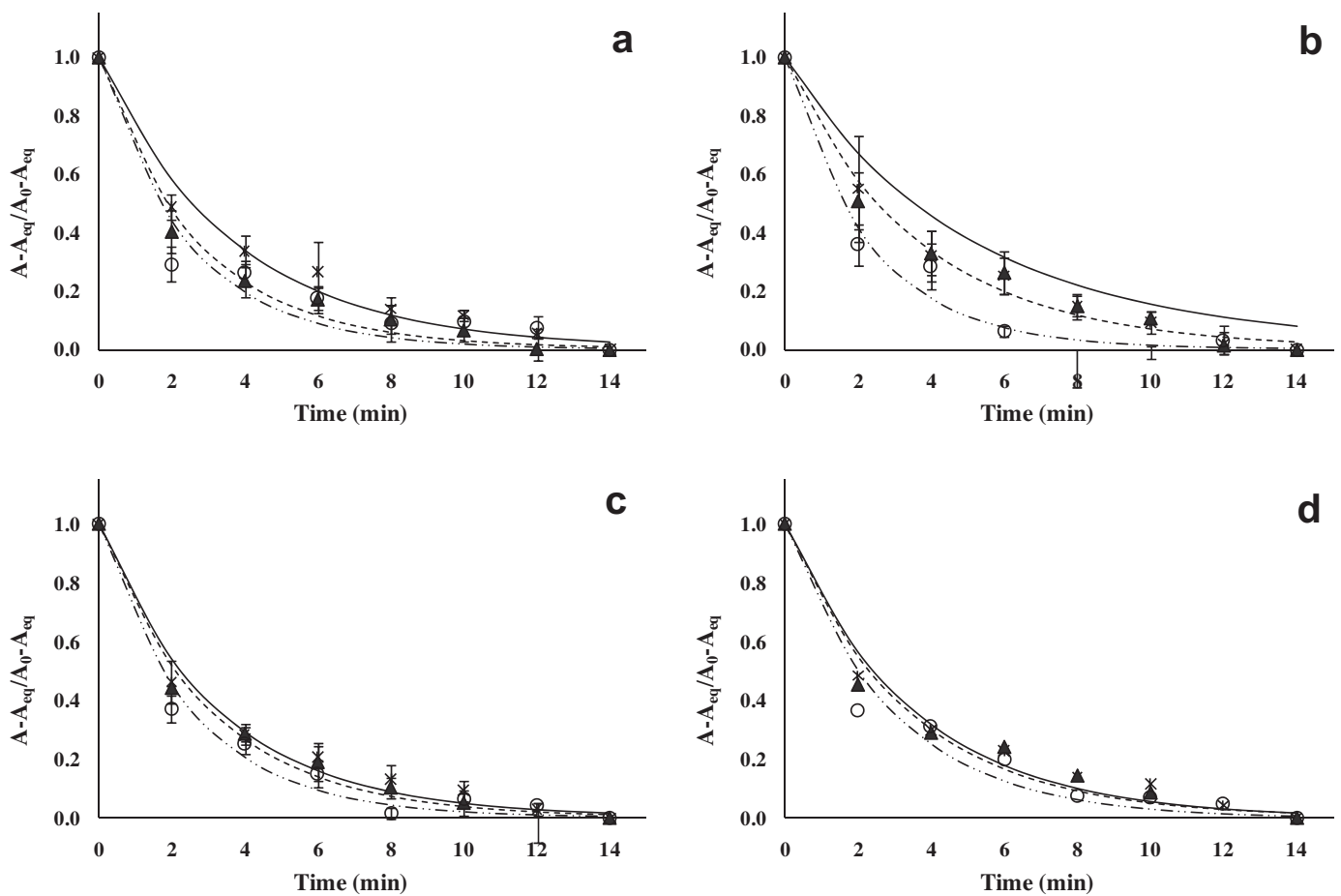

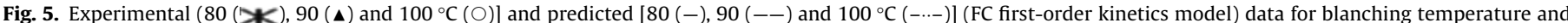

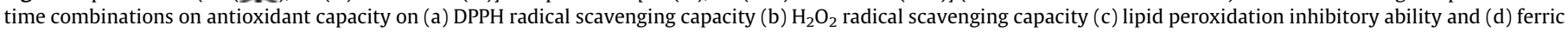
reducing antioxidant potential of York cabbage.

Please cite this article in press as: Jaiswal, A. K., et al. Kinetic evaluation of colour, texture, polyphenols and antioxidant capacity of Irish York cabbage after blanching treatment. Food Chemistry (2011), doi:10.1016/j.foodchem.2011.08.032 
radation kinetic parameter estimates, corresponding regression coefficients and MSE of York cabbage AO capacity losses due to blanching. Different AO systems showed a high degree of fit for all the models studied with FC first-order kinetic model being the most suitable. Experimental and predicted (FC first-order) data for the deterioration in AO capacity due to blanching at 80,90 and $100{ }^{\circ} \mathrm{C}$ are presented in Fig. 5. The $k$ value confirmed the effect of blanching temperature on the reduction of AO capacity. For the entire AO capacity analysis, the $k$ increases when the temperature increases from 80 to $100{ }^{\circ} \mathrm{C}$ (Table 2 ).

The temperature dependence of the AO capacity analysis rate constant was well expressed by the Arrhenius equation (Eq. (5)). The activation energies obtained from these data for different AO methods are presented in Table 4. The values were 35.05, 22.37, 21.53 and $9.05 \mathrm{~kJ} / \mathrm{m} \mathrm{K}$ for $\mathrm{H}_{2} \mathrm{O}_{2}$ RSC, DPPH RSC, LPO inhibitory ability and FRAP assay, respectively. Difference in the activation energies for different methods could be explained by the fact that different compounds or their synergistic effects were associated with a particular AO capacity assay. Higher activation energy implies that a smaller temperature change will degrade the AO capacity more rapidly.

\subsection{Effects of blanching on colour change}

Colour is one of the most important quality attributes of food materials. Chroma is the indicator of colour saturation and intensity. The higher its values are, the more desirable a food product is. Fresh York cabbage heads were bright green, as indicated by the CIE scale parameters: co-ordinate $a^{*}$ was $-3.45 ; b^{*}$ was 20.3 and the $L^{*}$ co-ordinate, associated with lightness, was 64.7 with a chroma value of $23.9 \pm 1.52$. Results showed that blanching had a severe effect on chroma; as the temperature and time of processing increased the value of chroma decreased. Similar findings were observed by Viña et al. (2007) and Lespinard, Goñi, Salgado, and Mascheroni (2009). These authors studied the effects of blanching on colour of Brussels sprouts and mushrooms and found that blanching leads to fading of colour from dark to light with increased temperature. The reduction in chroma could be due to degradation of chlorophyll accompanied with a loss of the liberated colouring compounds by migration into the blanching water. Kinetic studies of chlorophyll degradation have found this reaction to be temperature dependent (Koca, Karadeniz, \& Burdurlu, 2007; Weemaes, Ooms, Van Loey, \& Hendrickx, 1999).

\section{Table 3}

Kinetic parameter estimates, corresponding regression coefficient and mean square errors of York cabbage texture (firmness) and colour (chroma) degradation due to blanching.

\begin{tabular}{lrlll}
\hline & Temperature $\left({ }^{\circ} \mathrm{C}\right)$ & \multicolumn{2}{l}{ First order } \\
\cline { 3 - 5 } & & $k$ & $r^{2}$ & MSE \\
\hline Texture & 80 & $0.042 \pm 0.00$ & 0.937 & 0.002 \\
& 85 & $0.043 \pm 0.00$ & 0.957 & 0.015 \\
& 90 & $0.090 \pm 0.00$ & 0.967 & 0.002 \\
& 95 & $0.093 \pm 0.00$ & 0.943 & 0.003 \\
Zero order & 100 & $0.146 \pm 0.01$ & 0.985 & 0.001 \\
Colour & 80 & & & \\
& 85 & $0.543 \pm 0.10$ & 0.929 & 0.913 \\
& 90 & $0.612 \pm 0.06$ & 0.952 & 0.569 \\
& 95 & $0.633 \pm 0.08$ & 0.937 & 1.227 \\
& 100 & $0.648 \pm 0.09$ & 0.875 & 1.193 \\
& & $0.756 \pm 0.04$ & 0.962 & 0.672 \\
\hline
\end{tabular}

$k$, kinetic parameter estimates.

$r^{2}$, regression coefficient.

MSE, mean square errors.
Table 4

Activation energy and regression coefficient for different physicochemical properties.

\begin{tabular}{lcc}
\hline & $E_{\mathrm{a}}(\mathrm{kJ} / \mathrm{molK})$ & $r^{2}$ \\
\hline TPC & 11.54 & 0.901 \\
$\mathrm{TFC}$ & 9.22 & 0.870 \\
Texture & 33.80 & 0.908 \\
Colour & 15.73 & 0.910 \\
$\mathrm{DPPH}$ & 22.37 & 0.977 \\
$\mathrm{H}_{2} \mathrm{O}_{2}$ & 35.05 & 0.907 \\
$\mathrm{LPO}$ & 21.53 & 0.903 \\
FRAP & 9.05 & 0.880
\end{tabular}

$E_{a}$, activation energy.

$r^{2}$, regression coefficient.

TPC, total phenolic content.

TFC, total flavonoid content.

DPPH, 2,2-diphenyl-1-picrylhydrazyl free radical scavenging capacity.

$\mathrm{H}_{2} \mathrm{O}_{2}$, hydrogen peroxide scavenging assay.

LPO, lipid peroxidation in a haemoglobin-induced linoleic acid system.

FRAP, ferric reducing antioxidant potential.
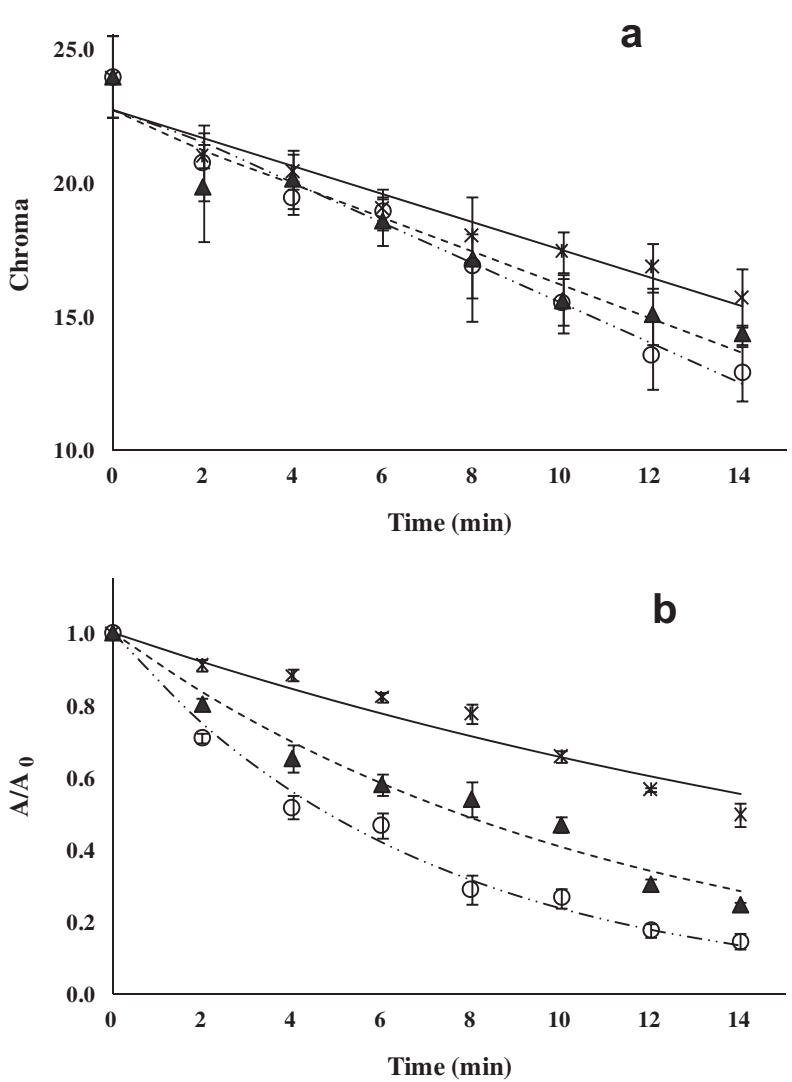

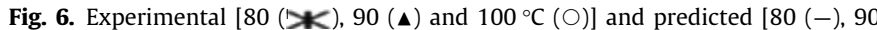
$(--)$ and $\left.100{ }^{\circ} \mathrm{C}(-\cdots-)\right]$ data for blanching temperature and time combinations on (a) colour (chroma) (zero order equation) and (b) texture (firmness) of York cabbage (first-order kinetics model).

Zero order kinetic model (Eq. (2)) was found to be appropriate for modelling the effect of blanching on York cabbage chroma with high $r^{2}$ ranging from 0.929 to 0.962 . Kinetic parameter estimates, corresponding regression coefficients and MSE of chroma due to blanching are included in Table 3. Experimental and predicted (zero order) data for three blanching temperature $(80,90$ and $100{ }^{\circ} \mathrm{C}$ ) and time combination on chroma are presented in Fig. 6a (similar results were obtained for 85 and $95^{\circ} \mathrm{C}$ (data not shown)). The $k$ value increases from 0.543 to $0.756 \mathrm{~min}^{-1}$ with an increase 
in temperature from 80 to $100{ }^{\circ} \mathrm{C}$. The temperature dependence of the chroma rate constant was expressed by the Arrhenius equation (Eq. (5)). The activation energy was estimated as $15.73 \mathrm{~kJ} / \mathrm{mol} \mathrm{K}$ $\left(r^{2}=0.910\right)$.

\subsection{Effects of blanching on textural properties}

Texture is one of the most significant quality constraints, which is essential for ensuring product acceptability. According to De Man (1976), texture can be defined as "the way in which the structural components of a food are arranged in a microand macrostructure and the external manifestations of this structure". In the present study, the maximum shearing force for fresh York cabbage was recorded as $73.1 \mathrm{~N}$. In contrast to changes in phytochemicals, textural properties of cabbage seemed to follow a different trend. A reduction in the range of $9-28.9 \%$ was observed in the first $2 \mathrm{~min}$. The loss of texture continued up to 14 min of blanching without reaching any equilibrium, which was contrary to the results for the phytochemical content. A significant reduction in firmness in the range of $43.2-50.3 \%$ was observed after $14 \mathrm{~min}$ at $80-85^{\circ} \mathrm{C}$, whereas at higher temperatures $\left(90-100{ }^{\circ} \mathrm{C}\right)$ a decrease of $83.0-87.6 \%$ was observed, thus indicating significant effect of blanching times and temperatures. However, firmness was better retained at lower temperature and longer time as compared to higher temperature and longer process time. During thermal processing, a range of enzymatic and chemical reactions occur, which alter the texture of processed fruits and vegetables. The chemical changes, such as solubilisation and depolymerisation of pectic polysaccharides, affect the constituents of the cell wall and middle lamella, thereby resulting in a major change in the firmness of fruits and vegetables (Nisha, Singhal, \& Pandit, 2006).

Since the degradation of texture was less as the blanching time was increased, first order kinetic equation with Arrhenius temperature dependence (Eqs. (3) and (5)) fitted well in the experimental data with $r^{2}$ ranging from 0.937 to 0.975 . Experimental and predicted (first-order kinetics model) data for three blanching temperatures $\left(80,90\right.$ and $100{ }^{\circ} \mathrm{C}$ ) and time combinations on the firmness are presented in Fig. 6(b). Similar results were obtained for the other two temperatures (data not shown). The $k$ increased from 0.042 to $0.146 \mathrm{~min}^{-1}$ when the temperature was increased from 80 to $100^{\circ} \mathrm{C}$ (Table 3). The activation energy was estimated as $33.8 \mathrm{~kJ} / \mathrm{mol} \mathrm{K}$, and the $r^{2}$ was 0.908 . In comparison to the reported values for other vegetables, the activation energy obtained was significantly lower, which is indicative that texture characteristics of York cabbage were highly sensitive to the blanching temperature.

\section{Conclusion}

The present study confirms that blanching had a deleterious effect on the texture, colour, phenolic contents and AO capacity of York cabbage. Degradation kinetics for the polyphenolic content and AO capacity follow FC first-order with Arrhenius reaction while texture followed first order Arrhenius reaction. Colour (chroma) showed Arrhenius dependence with zero order reaction. Minimal heat treatment in cooking practices, for example blanching, is recommended to prevent major loss of AO activity and various phytochemicals. This information will add to knowledge that will impact consumer food selection and enhance the ability to find the right balance of fresh and processed vegetables. Furthermore, this information can be useful for the food processing industry to develop new food products, which may require blanching.

\section{Acknowledgment}

The authors would like to acknowledge funding from the Irish government under the Technological Sector Research Scheme (Strand III) of the National Development Plan.

\section{References}

Amin, I., \& Lee, W. Y. (2005). Effect of different blanching times on antioxidant properties in selected cruciferous vegetables. Journal of the Science of Food and Agriculture, 85(13), 2314-2320.

Andarwulan, N., Batari, R., Sandrasari, D. A., Bolling, B., \& Wijaya, H. (2010). Flavonoid content and antioxidant activity of vegetables from Indonesia. Food Chemistry, 121(4), 1231-1235.

Bunea, A., Andjelkovic, M., Socaciu, C., Bobis, O., Neacsu, M., Verhé, R., et al. (2008). Total and individual carotenoids and phenolic acids content in fresh, refrigerated and processed spinach (Spinacia oleracea L.). Food Chemistry, 108(2), 649-656.

De Man, J. M. (1976). Mechanical properties of foods. In J. M. De Man, P. W. Voisey, V. F. Pasper, \& D. W. Stanley (Eds.), Rheology and texture in food quality (pp. 8-27). Westport: The AVI Publishing Company.

Ganesan, P., Kumar, C. S., \& Bhaskar, N. (2008). Antioxidant properties of methanol extract and its solvent fractions obtained from selected Indian red seaweeds. Bioresource Technology, 99(8), 2717-2723.

Gonçalves, E. M., Pinheiro, J., Abreu, M., Brandão, T. R. S., \& Silva, C. L. M. (2010). Carrot (Daucus carota L.) peroxidase inactivation, phenolic content and physical changes kinetics due to blanching. Journal of Food Engineering, 97(4), 574-581.

Hollman, P. C. H. (2001). Evidence for health benefits of plant phenols: Local or systemic effects? Journal of the Science of Food and Agriculture, 81(9), 842-852.

Jaiswal, A. K., Rajauria, G., Abu-Ghannam, N., \& Gupta, S. (2011). Effect of different solvents on polyphenolic content, antioxidant capacity and antibacterial activity of Irish York cabbage. Journal of Food Biochemistry. doi:10.1111/ j.1745-4514.2011.00545.

Joubert, E. (1990). Effect of batch extraction conditions on extraction of polyphenols from rooibos tea (Aspalathus linearis). International Journal of Food Science $\mathcal{E}$ Technology, 25(3), 339-343.

Kim, D. O., Padilla-Zakour, O. I., \& Griffiths, P. D. (2004). Flavonoids and antioxidant capacity of various cabbage genotypes at juvenile stage. Journal of Food Science, 69(9), C685-C689.

Koca, N., Karadeniz, F., \& Burdurlu, H. S. (2007). Effect of pH on chlorophyll degradation and colour loss in blanched green peas. Food Chemistry, 100(2), 609-615.

Lespinard, A. R., Goñi, S. M., Salgado, P. R., \& Mascheroni, R. H. (2009). Experimental determination and modeling of size variation, heat transfer and quality indexes during mushroom blanching. Journal of Food Engineering, 92(1), 8-17.

Lin, J. Y., \& Tang, C. Y. (2007). Determination of total phenolic and flavonoid contents in selected fruits and vegetables, as well as their stimulatory effects on mouse splenocyte proliferation. Food Chemistry, 101(1), 140-147.

Liu, S. C., Lin, J. T., Wang, C. K., Chen, H. Y., \& Yang, D. J. (2009). Antioxidant properties of various solvent extracts from lychee (Litchi chinenesis Sonn.) flowers. Food Chemistry, 114(2), 577-581.

Morales-Blancas, E. F., Chandia, V. E., \& Cisneros-Zevallos, L. (2002). Thermal inactivation kinetics of peroxidase and lipoxygenase from broccoli, green asparagus and carrots. Journal of Food Science, 67(1), 146-154.

Nisha, P., Singhal, R. S., \& Pandit, A. B. (2006). Kinetic modeling of texture development in potato cubes (Solanum tuberosum L.), green gram whole (Vigna radiate L.) and red gram splits (Cajanus cajan L.). Journal of Food Engineering, 76(4), 524-530.

Oboh, G. (2005). Effect of blanching on the antioxidant properties of some tropical green leafy vegetables. Lebensmittel-Wissenschaft und-Technologie, 38(5), 513-517.

Papetti, A., Daglia, M., \& Gazzani, G. (2002). Anti- and pro-oxidant activity of water soluble compounds in Cichorium intybus var. silvestre (Treviso red chicory). Journal of Pharmaceutical and Biomedical Analysis, 30(4), 939-945.

Puupponen-Pimiä, R., Häkkinen, S. T., Aarni, M., Suortti, T., Lampi, A.-M., Eurola, M., et al. (2003). Blanching and long-term freezing affect various bioactive compounds of vegetables in different ways. Journal of the Science of Food and Agriculture, 83(14), 1389-1402.

Rajauria, G., Jaiswal, A. K., Abu-Ghannam, N., \& Gupta, S. (2010). Effect of hydrothermal processing on colour, antioxidant and free radical scavenging capacities of edible Irish brown seaweeds. International Journal of Food Science $\mathcal{E}$ Technology, 45(12), 2485-2493.

Ranilla, L. G. L., Genovese, M. I. S., \& Lajolo, F. M. (2009). Effect of different cooking conditions on phenolic compounds and antioxidant capacity of some selected Brazilian bean (Phaseolus vulgaris L.) cultivars. Journal of Agricultural and Food Chemistry, 57(13), 5734-5742.

Singh, B. K., Sharma, S. R., \& Singh, B. (2009). Heterosis for mineral elements in single cross-hybrids of cabbage (Brassica oleracea var. capitata L.). Scientia Horticulturae, 122(1), 32-36.

Sroka, Z., \& Cisowski, W. (2003). Hydrogen peroxide scavenging, antioxidant and anti-radical activity of some phenolic acids. Food and Chemical Toxicology, 41(6), 753-758.

Taveira, M., Pereira, D. M., Sousa, C., Ferreres, F., Andrade, P. B., Martins, A., et al. (2009). In vitro cultures of Brassica oleracea L. var. costata DC: Potential plant 
bioreactor for antioxidant phenolic compounds. Journal of Agricultural and Food Chemistry, 57(4), 1247-1252.

Viña, S. Z., Olivera, D. F., Marani, C. M., Ferreyra, R. M., Mugridge, A., Chaves, A. R., et al. (2007). Quality of Brussels sprouts (Brassica oleracea L. gemmifera DC) as affected by blanching method. Journal of Food Engineering, 80(1), 218-225.

Volden, J., Borge, G. I. A., Bengtsson, G. B., Hansen, M., Thygesen, I. E., \& Wicklund, T. (2008). Effect of thermal treatment on glucosinolates and antioxidant-related parameters in red cabbage (Brassica oleracea L. ssp. capitata f. rubra). Food Chemistry, 109(3), 595-605.
Weemaes, C. A., Ooms, V., Van Loey, A. M., \& Hendrickx, M. E. (1999). Kinetics of chlorophyll degradation and colour loss in heated broccoli juice. Journal of Agricultural and Food Chemistry, 47(6), 2404-2409.

Wen, T. N., Prasad, K. N., Yang, B., \& Ismail, A. (2010). Bioactive substance contents and antioxidant capacity of raw and blanched vegetables. Innovative Food Science E Emerging Technologies, 11(3), 464-469.

Yamaguchi, T., Katsuda, M., Oda, Y., Terao, J., Kanazawa, K., Oshima, S., et al. (2003). Influence of polyphenol and ascorbate oxidases during cooking process on the radical-scavenging activity of vegetables. Food Science and Technology Research, 9(1), 79-83. 